\title{
Effect of Extraction Solvents on Total Phenolic Contents and in vitro Antioxidant Activity of the Leaves of Lippia adoensis var. Koseret Sebsebe
}

\author{
Engeda Dessalegn. ${ }^{1} \quad$ Geremew Bultosa $^{2} \quad$ Gulelat Desse Haki $^{3} \quad$ H. P. Vasantha Rupasinghe ${ }^{4}$ \\ 1.Department of Chemistry, Hawassa College of Education, P.O. Box 115, Hawassa, Ethiopia \\ 2.Department of Food Science and Technology, Botswana University of Agriculture and Natural Resource, \\ Private Bag 0027, Gaborone, Botswana \\ 3.Center for Food Science and Nutrition, College of Natural Science, Addis Ababa University, P.O. Box 1176, \\ Addis Ababa Ethiopia \\ 4.Department of Environmental Sciences, Faculty of Agricultural College, Dalhousie University P.O. Box 550, \\ Canada
}

\begin{abstract}
Lippia. adoensis var. koseret is an endemic herb to Ethiopia and is traditionally used as food flavoring and traditional medicine. This paper reported the total phenolic and flavonoid contents, and in vitro antioxidant activity of various extracts from the dried leaf of this herb. Aqueous: methanol $(20: 80, \mathrm{v} / \mathrm{v})$ extract contained highest amount of total phenolic $(67.61 \pm 9.89 \mathrm{mg}$ of gallic acid equivalent/g). Total flavonoid contents were highest in acetone extract $(25.24 \pm 0.43 \mathrm{mg}$ of quercetin equivalent $/ \mathrm{g})$. An increase in the extracted concentration resulted in an increase of antioxidant power for all the extracts. The aqueous: methanol $(20: 80, \mathrm{v} / \mathrm{v})$ extract showed highest DPPH radical scavenging $\left(\mathrm{IC}_{50}=10.96 \pm 0.42 \mu \mathrm{g} / \mathrm{ml}\right)$ iron reducing power $\left(\mathrm{IC}_{50}=123.97 \pm 3.23 \mu \mathrm{g} / \mathrm{ml}\right)$, total antioxidant activity $\left(105.32 \pm 10.67 \mathrm{mg}\right.$ ascorbic acid equivalent/g), and iron chelating activity $\left(\mathrm{IC}_{50}=81.31 \pm\right.$ $15.94 \mu \mathrm{g} / \mathrm{ml})$ than other four solvents used. Total phenolics well correlated with DPPH $\left(\mathrm{R}^{2}=0.88, \mathrm{p}<0.05\right)$ and Ferric reducing power $\left(\mathrm{R}^{2}=0.77 \mathrm{p}<0.05\right)$. Whereas, total flavonoid content well correlated with total antioxidant $\left(R^{2}=0.73 p<0.05\right)$. The study showed the antioxidants activities of the crude extract were variable when extracted by different solvents indicating a high potential to be used as natural antioxidants in preventing various oxidative stresses and as food preservatives.
\end{abstract}

Keywords: Antioxidant; $\alpha$ - Amylase; Phenolic compounds; Herbs; Lippia adoensis var. koseret

DOI: $10.7176 / \mathrm{FSQM} / 94-04$

Publication date: February $29^{\text {th }} 2020$

\section{INTRODUCTION}

The genus Lippia (Verbenaceae) is widely distributed in tropical and subtropical regions of the Americas and Africa, and it consists of approximately 200 species of herbs, shrubs, and small trees (Terblanche \& Kornelius, 1996). Most of these species are traditionally utilized in the indigenous systems of medicine for the treatment of a variety of human aliments. The majority of them have been used for the treatment of Stomach ailments, cardiovascular troubles, coughs, colds and asthma, tranquillizing remedy, prevention of gastritis, and headache (Danielo et al., 2006; Raul et al, 2011; Mamun-Or-Rashid et al., 2013;). Some of the species exhibited strong antioxidant (Naznin and Hasan, 2009), antidiabetic (Rangachari and Savarimuthu 2011), insecticidal (Okonkwo \& Ohaeri 2012) and antimicrobial (Danielo et al., 2007; Sandra et al., 2012; Suzana et al., 2011) activities.

L. adoensis is one of the five indigenous Lippia species in Ethiopia where it occurs as an erect woody shrub up to 1-3m tall (Hedberg et al., 2006). It is endemic herb to the afromontane region of Ethiopia. The leaves of $L$. adoensis are used in Ethiopian traditional medicine for the treatment of various skin diseases including eczema and superficial fungal infections (Hailu et al., 2005), antimicrobial activity (Gemechu et al., 2015), also for food flavoring agent and preservative (Riot et al., 2005). Two varieties are recognized in Ethiopia, the wild variety (var. adoensis) and the cultivated variety (var. koseret sebsebe). L. adoensis var. koseret sebsebe, locally known as koseret, is widely grown in the central and southern highlands of the country. Traditionally, the dried leaves are used as one of the ingredients in the preparation of spiced butter. The special taste and flavor of the Gurage kitfo (minced meat with spiced butter) is attributed to essential oil imparted by the leaves (Nigist \& Sebsebe, 2009). The dried leaves powdered together with barely eaten to get relief from stomach complaints (Megersa et al, 2013). The chemical compositions of $L$. adoensis var koseret, investigated so far are essential oils. Lonalool is the major component, and appreciable amount of sesquiterpene hydrocarbons (germacrene, $\alpha$-copaene, $\beta$-cadinene, and, $\beta$ caryophyllene) and uncommon monoterpene ketone, 2-methyl-6-methylene-2, 7-octadien-4-one (ipsdienone), were also found in the essential oil (Berhanu A. et al, 2001).

So far studies have investigated the in vitro antioxidant activity (using DPPH assay) of the essential oil of $L$. adoensis var. koseret (Riot et al., 2005; Workalemahu et al., 2007). To our knowledge, there is no report on total phenolic contents and in vitro antioxidant (using different assays) and possible variations in the levels of total 
phenolic and flavonoid contents and the antioxidant activity of various solvent extracts from this dietary herb. Therefore, the objective of the present study was to evaluate and compare the total phenolic and flavonoid contents, antioxidant properties (by DPPH, reducing power assay, total antioxidant, and ferrous chelating activity) of petroleum ether, water, acetone, methanol, and aqueous: methanol $(20: 80, \mathrm{v} / \mathrm{v})$ extracts of this herb. Furthermore, the correlation between total phenolic content and the antioxidant capacity was also evaluated.

\section{Materials and Methods \\ Chemicals}

Gallic acid, butylated hydroxytoluene (BHT), Folin-Ciocalteu reagent, 2, 2-diphenyl-1-picrylhydrazyl (DPPH), quercetin, ferrozine, and L-ascorbic acid, were purchased from Sigma-Aldrich. The other chemicals and solvents used in this experiment were of analytical grade.

\section{Plant Materials}

Fresh leaves of L. adoensis var. koseret were collected from $5 \mathrm{~km}$ south east of Chuko town, Sidama zone, South Ethiopia in April, 2014 and identified at the Biology Department, College of Natural Sciences of Addis Ababa University, Addis Ababa, Ethiopia. The voucher specimen was deposited at the center of Food science and Nutrition.

\section{Preparation of Plant Extracts}

Fresh leaves of $L$. adoensis var. koseret were air dried for ten days and then ground to fine powder using electric grinder (FM100 model, China). The petroleum ether, water, acetone, methanol, and aqueous: methanol (20:80, $\mathrm{v} / \mathrm{v}$ ) extracts of all were prepared by dissolving $10 \mathrm{~g}$ of the leaves fine powder separately in $100 \mathrm{ml}$ each solvent. The contents were kept in orbital shaker for $6 \mathrm{~h}$ at room temperature. Thereafter, each extract was filtered using Whatman no.1 filter paper and evaporated to dryness under vacuum at $40^{\circ} \mathrm{C}$ by using a rotary evaporator (Buchi, 3000 series, Switzerland). For each solvent, the extraction was done in triplicate and the resulting extracts were stored in a sealed plastic container at $4^{\circ} \mathrm{C}$ until further investigation. Unless specifically mentioned all analysis were conducted on triplicate analysis.

\section{Determination of Total Phenolic Contents}

Total phenolic content was estimated by Folin-Ciocalteu method as described in Velioglu et al. (1998) with slight modification using gallic acid as standard. To $100 \mu \mathrm{l}$ of the extract $(1 \mathrm{mg} / \mathrm{ml}), 1 \mathrm{ml}$ Folin-Ciocalteu reagent (diluted ten times) was added and the mixture was left for $5 \mathrm{~min}$ and then $1 \mathrm{~mL}(75 \mathrm{~g} / \mathrm{l})$ of sodium carbonate was added. The absorbance of the resulting blue color was measured at $765 \mathrm{~nm}$ with a UV- visible spectrophotometer (JENWAY, 96500, UK) after incubation for $90 \mathrm{~min}$ at room temperature. The total phenolic content was estimated from gallic acid $(1-100 \mu \mathrm{g} / \mathrm{ml})$ calibration curve $\left(\mathrm{y}=0.018 \mathrm{x}+0.021, \mathrm{R}^{2}=0.99\right)$ and results were expressed as milligram gallic acid equivalent/gram of dried extract (mgGAE/g).

\section{Determination of Total Flavonoid Content}

Total flavonoid content was determined by aluminum method (Ruche and Rekha, 2017) using quercetin as a standard with minor modification. The analysis was based on the formation of pink color of flavonoid-aluminum complex. The extracts $(1 \mathrm{ml}, 1 \mathrm{mg} / \mathrm{ml})$ were diluted with $1.25 \mathrm{ml}$ distilled water and $75 \mu \mathrm{l}$ of $5 \% \mathrm{NaNO}_{2}$ solution followed the addition of $150 \mu \mathrm{L}$ of $10 \% \mathrm{AlCl}_{3} 5 \mathrm{~min}$ later. After $6 \mathrm{~min}, 1 \mathrm{~mL} \mathrm{NaOH}$ and $0.6 \mathrm{~mL}$ distilled water were added. The absorbance was measured against the blank at $510 \mathrm{~nm}$ using spectropkotometer. The total flavonoid content was determined using a standard curve of quercetin at $(1-40 \mu \mathrm{g} / \mathrm{ml})$ and values were calculated as milligram quercetin equivalents/gram of dried extract $(\mathrm{mgQRE} / \mathrm{g})$ using the following equation: $\mathrm{y}=0.023 \mathrm{x}+$ $0.101, \mathrm{R}^{2}=0.99$

\section{Determination of Antioxidant Activity DPPH method}

The 2, 2-diphenyl-1-picrylhydrazyl (DPPH) radical scavenging activity of the extracts from L. adoensis var. koseret leaves was determined as described by Hemlata \& Pratima. (2013) with slight modification. Different concentrations (10 to $100 \mu \mathrm{g} / \mathrm{ml})$ of the extracts were taken in different test tubes. Freshly prepared DPPH solution $(2 \mathrm{ml}, 0.06 \%, \mathrm{w} / \mathrm{v})$ in methanol was added in each of the test tubes containing $1 \mathrm{ml}$ of the extract. The reaction mixture and the reference standards (ascorbic acid and BHT) were vortexed and left to stand at room temperature in the dark for $30 \mathrm{~min}$. The absorbance of the resulting solution was then taken at $520 \mathrm{~nm}$. Methanol was used as blank. The ability to scavenge the DPPH radical was calculated using the following equation:

$$
D P P H \text { scavenging }(\%)=\frac{(A c-A s)}{A c} \times 100
$$

Where $A \mathrm{c}$ is the absorbance of the control and $A \mathrm{~s}$ is the absorbance in presence of the sample of the extracts. 
The antioxidant activity of the extract was expressed as $\mathrm{IC}_{50}$. The $\mathrm{IC}_{50}$ value was defined as the concentration (in $\mu \mathrm{g} / \mathrm{ml}$ ) of extracts that scavenges the DPPH radical by $50 \%$.

\section{Ferric ion reducing power}

The presence of antioxidants in the extract causes the reduction of the yellow ferric/ferricyanide complex to the ferrous form which can be monitored by measuring the formation of Perl's Prussian blue at $700 \mathrm{~nm}$ (Amarowicza et al., 2016). This assay was carried out as described by Abiola et al, (2016). Plant extract (1 ml) solution (final concentration $50-1000 \mu \mathrm{g} / \mathrm{ml})$ was mixed with $2.5 \mathrm{ml}$ sodium phosphate buffer $(0.2 \mathrm{M}$, pH 6.6) and $2.5 \mathrm{ml}$ of $1 \%$ potassium ferricyanide. Then the mixture was incubated at $50^{\circ} \mathrm{C}$ for $20 \mathrm{~min}$. Trichloroacetic acid $(2.5 \mathrm{ml}, 10 \%)$ was added to the mixture, which was then centrifuged at $3000 \mathrm{rpm}$ (Centurion, 1000 series, UK) for 5 min. Finally, $2.5 \mathrm{ml}$ of the supernatant solution was mixed with $2.5 \mathrm{ml}$ of distilled water and $0.5 \mathrm{ml} \mathrm{FeCl}_{3}(0.1 \%)$ and absorbance was measured at $700 \mathrm{~nm}$. BHT was used as reference material. All tests were performed in triplicate. Increase in absorbance of the reaction indicated the reducing power of the samples. A higher absorbance indicated a higher reducing power. $\mathrm{IC}_{50}$ values $(\mu \mathrm{g} / \mathrm{ml})$ were calculated and indicate the effective concentration at which the absorbance was 0.5 for reducing power (Rodrigo et al., 2011).

\section{Total antioxidant activity using phosphomolybdenum method}

The total antioxidant activity of the crude extracts was evaluated by the phosphomolybdenum method (Prieto et al., 1999) with slight modification. The method is based on the reduction of Mo (VI) to Mo (V) by the antioxidant compounds or crude extract and subsequent formation of green Mo (V) complexes with a maximal absorption at $695 \mathrm{~nm}$ at acidic medium (Mohamed et al., 2011). Plant extract $(0.3 \mathrm{ml}, 0.8$ and $1 \mathrm{mg} / \mathrm{ml})$ was mixed with $3 \mathrm{ml}$ of reagent solution $(0.6 \mathrm{M}$ sulphuric acid, $28 \mathrm{mM}$ sodium phosphate and $4 \mathrm{mM}$ ammonium molybdate). The samples were incubated at $95^{\circ} \mathrm{C}$ for $90 \mathrm{~min}$, cooled to room temperature and absorbance was measured at $695 \mathrm{~nm}$ and methanol $(3 \mathrm{ml})$ was used as blank. The total antioxidant activity was expressed as milligram ascorbic acid equivalent/gram of dried extract (mg AAE/g) based on the calibration curve; $y=0.03 x+0.241, R^{2}=0.99(p<$ $0.001)$.

\section{Chelating effects on ferrous ions}

The ferrous chelating activity was determined according to the method of Mohammad et al. (2008) with minor modification. Various concentrations $(100-800 \mu \mathrm{g} / \mathrm{ml})$ of the extracts $(3 \mathrm{ml})$ in methanol were added to a solution of $2 \mathrm{mM} \mathrm{FeCl}_{2}(0.05 \mathrm{ml})$. The reaction was initiated by the addition of $5 \mathrm{mM}$ ferrozine $(0.1 \mathrm{ml})$. Then, the mixture was shaken vigorously and left at room temperature for $10 \mathrm{~min}$. Absorbance of the solution was measured at 562 nm. Ethylenediamine tetraacetic acid (EDTA), L-ascorbic acid, quercetin and BHT were used as a control. The inhibition percentage of ferrozine- $\mathrm{Fe}^{2+}$ complex formation was calculated by using the formula given below:

$$
\text { Metal chelating effect }(\%)=\frac{(A c-A s)}{A c} \times 100
$$

Where Ac is control absorbance (the control contains $\mathrm{FeCl}_{2}$ and ferrozine, complex formation molecules) and As is test sample absorbance.

\section{Statistical Analysis}

The data were subjected to analysis of variance (ANOVA) and Duncan's multiple range tests were used for mean separation at $\mathrm{p}<0.05$. Linear regression analysis was used to calculate $\mathrm{IC}_{50}$ value. Pearson correlations among antioxidant activities, total phenolic and flavonoid contents were considered at $\mathrm{p}<0.05$.

\section{Results and Discussions}

Determination of Total Phenolic and Flavonoid Contents

The total phenolic contents in various solvent extracts from the leaf of L. adoensis var. koseret varied widely, ranging from $10.2 \pm 2.2$ to $67.6 \pm 9.96 \mathrm{mgGAE} / \mathrm{g}$ (Table 1). The total phenolic content followed the order: aqueous: methanol $(20: 80, \mathrm{v} / \mathrm{v})>$ methanol $>$ water $>$ acetone $>$ petroleum ether extracts. There was no significant difference $(p>0.05)$ in total phenolic content between acetone and water but these values were significantly different $(p<$ $0.05)$ from petroleum ether, methanol, and aqueous: methanol $(20: 80, \mathrm{v} / \mathrm{v})$ extracts. 
Table 1 Total phenolic content (mgGAE/ g) of $L$. adoensis var. koseret

\begin{tabular}{lll}
\hline \multicolumn{1}{c}{ Extract } & $\begin{array}{c}\text { Total phenolic } \\
(\mathrm{mgGAE} / \mathrm{g})^{*} \pm \mathrm{SEM}\end{array}$ & $\begin{array}{c}\text { Total flavonoid** } \\
(\mathrm{mgQRE} / \mathrm{g} \pm \text { SEM }\end{array}$ \\
\hline Petroleum ether & $10.2 \pm 2.2^{\mathrm{a}}$ & - \\
Water & $33.9 \pm 1.6^{\mathrm{b}}$ & $6.6 \pm 0.2^{\mathrm{a}}$ \\
Acetone & $26.7 \pm 1.7^{\mathrm{b}}$ & $25.3 \pm 0.4^{\mathrm{c}}$ \\
Methanol & $52.2 \pm 5.4^{\mathrm{c}}$ & $15.2 \pm 1.5^{\mathrm{b}}$ \\
Aqueous : methanol $(20: 80, \mathrm{v} / \mathrm{v})$ & $67.6 \pm 9.9^{\mathrm{d}}$ & $22.8 \pm 0.3^{\mathrm{c}}$ \\
\hline
\end{tabular}

Where $*$ and $* *$ are total phenolic and total flavonoids expressed as gallic acid and quercetin equivalents, respectively. Values are expressed as mean $\pm \operatorname{SEM}(n=3)$ from triplicate experiments. Means with different letters in a column were significantly different at the level of $\mathrm{p}<0.05$.

The total flavonoid contents (mgQRE/g) varied from $6.6 \pm 0.2$ to $25.3 \pm 0.3$ and decreased in the order of acetone > aqueous: methanol $(20: 80, \mathrm{v} / \mathrm{v})>$ methanol $>$ water extracts (Table 1$)$. Flavonoids were not detected in petroleum ether extract. The total flavonoid contents in water, acetone and methanol extracts were significantly different $(\mathrm{p}<0.05)$, but in the acetone extract was not significantly different $(\mathrm{p}>0.05)$ from aqueous: methanol $(20: 80, v / v)$ extract.

\section{Determination of Antioxidant Activity DPPH scavenging}

The DPPH radical scavenging effects of L. adoensis var. koseret leaf extracts are shown in Figure 1. DPPH radical is scavenged by antioxidants through the donation of hydrogen forming the reduced DPPH. The color changes from purple 2, 2-diphenyl-1-picrylhydrazyl radical to reduced yellow diamagnetic 2, 2-diphenyl-1-picrylhydrazine molecule, which can be quantified by its absorbance reduction at wavelength $520 \mathrm{~nm}$ (Engeda et al., 2015). As the concentration of sample increased, the percent inhibition of DPPH radical also increased (Durairaj et al., 2008). At the concentration of $100 \mu \mathrm{g} / \mathrm{ml}$ used, the scavenging effect of ascorbic acid, BHT, and L. adoensis var. koseret extracts (aqueous: methanol (20:80, v/v), acetone, methanol, petroleum ether and water), on the DPPH radical scavenging decreased in the order of L- ascorbic acid $>$ BHT $>$ aqueous: methanol $(20: 80, \mathrm{v} / \mathrm{v})>$ methanol $>$ water $>$ acetone $>$ petroleum ether, which were $97.30 \pm 3.45 \%, 94.70 \pm 14.57 \%, 93.78 \pm 8.40 \%, 80.08 \pm 9.71 \%$, $79.64 \pm 5.05 \%, 66.08 \pm 6.19 \%$, and $53.03 \pm 3.31 \%$, respectively.

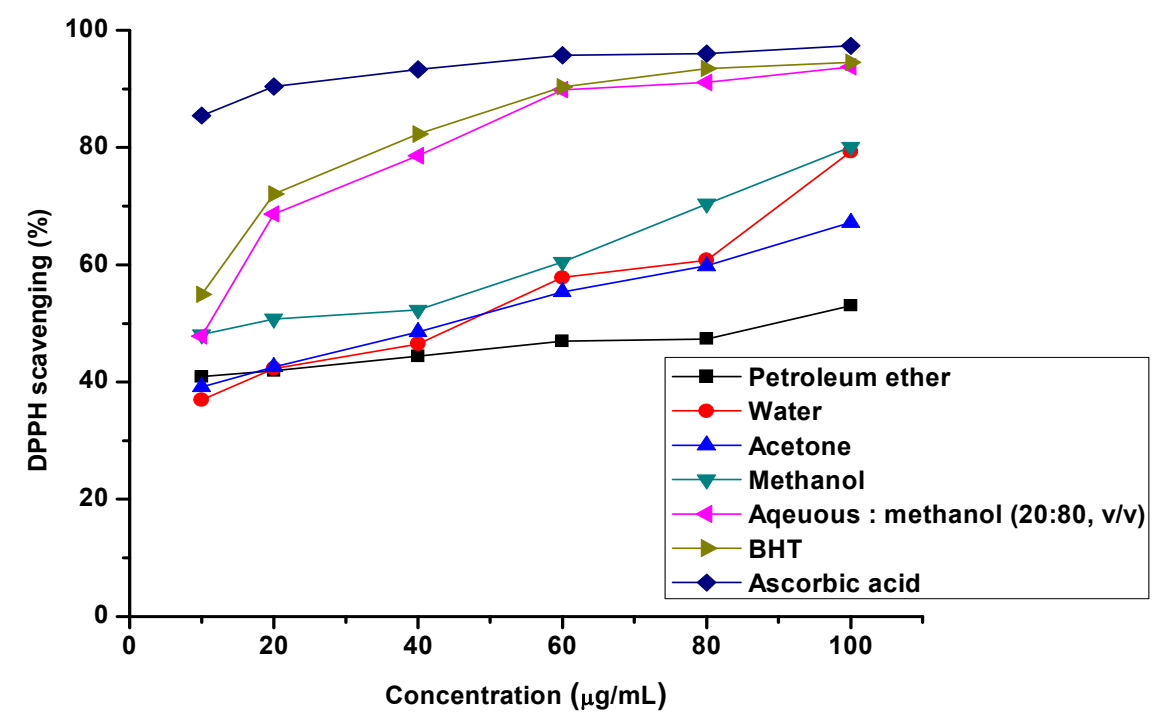

Figure1 DPPH radical scavenging activity (\%) of petroleum ether, water, acetone, methanol, and aqueous: methanol (20:80, v/v) extracts from dried leaf of L. adoensis var. koseret and controls (L-ascorbic acid and BHT). Values are average of triplicate measurements (mean $\pm \mathrm{SEM}$ ).

The $\mathrm{IC}_{50}$ values of all the extracts were calculated from plotted graph of percentage scavenging activity against concentration of the extracts (Table 2). The lower the $\mathrm{IC}_{50}$ value, the higher is the scavenging potential. The $\mathrm{IC}_{50}$ values ranged from $10.96 \pm 0.42 \mu \mathrm{g} / \mathrm{ml}$ for aqueous: methanol $(20: 80, \mathrm{v} / \mathrm{v})$ extract to $90.71 \pm 3.77 \mu \mathrm{g} / \mathrm{ml}$ for petroleum ether extract. Strongest scavenging activity (lower $\mathrm{IC}_{50}$ values) was recorded for aqueous: methanol $(20: 80, \mathrm{v} / \mathrm{v})$ extract which appeared more than four times stronger than that of water and acetone extracts and more than eight times stronger than that of petroleum ether extract. The $\mathrm{IC}_{50}$ values of water and acetone extracts were 
not found to be significantly different $(\mathrm{p}>0.05)$, but these values were significantly different from the $\mathrm{IC}_{50}$ values of petroleum ether, methanol, and aqueous: methanol (methanol: water, 80:20, v/v) extracts. The $\mathrm{IC}_{50}$ values of Lascorbic acid and BHT were tested as references. The $\mathrm{IC}_{50}$ values were $6.11 \pm 0.20 \mu \mathrm{g} / \mathrm{ml}$ for L- ascorbic acid and BHT showed $50 \%$ inhibition at $8.70 \pm 0.19 \mu \mathrm{g} / \mathrm{ml}$ The $\mathrm{IC}_{50}$ values of water, petroleum ether, acetone and methanol extracts were found to be significantly different $(\mathrm{p}<0.05)$ from BHT and L-ascorbic acid $\mathrm{IC}_{50}$ values, while that of the aqueous: methanol $(20: 80, v / v)$ extract was found to be similar $(p>0.05)$.

The antioxidant activity of petroleum ether extract of the present study showed weakest DPPH radical scavenging activity. Similar results were found for hexanoic extract of other species of the same genus (Junya et al., 2012). Similarly, the DPPH scavenging activity of methanol extract of Lippia alba (Alba and Hasan., 2009) was weaker $\left(\mathrm{IC}_{50}=34.4 \mu \mathrm{g} / \mathrm{ml}\right)$ than that of the present study $\left(\mathrm{IC}_{50}=18.57 \pm 3.49 \mu \mathrm{g} / \mathrm{ml}\right)$. Also the aqueous extract of the present study showed stronger DPPH scavenging than that of L. javanica $\left(\mathrm{IC}_{50}=195 \mu \mathrm{g} / \mathrm{mL}\right.$ ) (Abiola et al., 2016). But the methanol extract of the present study showed weaker DPPH scavenging power than that of $L$. nodiflora (Durairaj et al., 2008) $\left(\mathrm{IC}_{50}=12.03 \mu \mathrm{g} / \mathrm{ml}\right)$. This suggested that polar extracts of dried leaf extract of $L$. adoensis var. koseret contain higher phenolic compounds that can donate electron/hydrogen easily and stabilizes free radicals.

Table $2 \mathrm{IC}_{50}(\mu \mathrm{g} / \mathrm{ml} \pm \mathrm{SEM})$ values of DPPH scavenging, iron reducing and, ferrous chelating activities in various solvent extracts from leaf of $L$. adeonsis var. koseret.

\begin{tabular}{llll}
\hline Extract & DPPH assay & Reducing power & Iron chelating activity \\
\hline Petroleum ether & $90.71 \pm 3.77^{\mathrm{d}}$ & $>1 \times 10^{3}$ & $>1 \times 10^{3}$ \\
Water & $45.88 \pm 0.27^{\mathrm{c}}$ & $>1 \times 10^{3}$ & $191.98 \pm 13.49^{\mathrm{b}}$ \\
Acetone & $43.91 \pm 2.86^{\mathrm{c}}$ & $355.47 \pm 10.37^{\mathrm{c}}$ & $423.10 \pm 7.58^{\mathrm{c}}$ \\
Methanol & $18.57 \pm 3.49^{\mathrm{b}}$ & $167.65 \pm 5.62^{\mathrm{b}}$ & $418.56 \pm 7.55^{\mathrm{c}}$ \\
Aqueous : methanol & $10.96 \pm 0.42^{\mathrm{a}}$ & $123.97 \pm 3.23^{\mathrm{b}}$ & $81.31 \pm 15.94^{\mathrm{a}}$ \\
$(20 ; 80, \mathrm{v} / \mathrm{v})$ & & & \\
BHT & $8.70 \pm 0.19^{\mathrm{a}}$ & $44.85 \pm 1.02^{\mathrm{a}}$ & $>1 \times 10^{3}$ \\
Ascorbic acid & $6.11 \pm 0.20^{\mathrm{a}}$ & & $>1 \times 10^{3}$ \\
Quercetin & & & $>1 \times 10^{3}$ \\
EDTA & & & $50.15 \pm 0.60^{\mathrm{a}}$ \\
\hline
\end{tabular}

Values are expressed as mean \pm SEM $(n=3)$ from triplicate experiments. Means with different letters in a column were significantly different at the level of $\mathrm{p}<0.05$.

\section{Ferric reducing power}

Ferric ion reduction is often used as an indicator of electron-donating activity, which is an important mechanism of phenolic antioxidant reaction (Rohman et al. 2010). Figure 2 shows the reducing powers of the all the extracts. Reducing power measures the reductive ability of an antioxidant and is assessed by the transformation of Fe(III) to $\mathrm{Fe}$ (II) in the presence of sample extract. An increase in the absorbance of the control (BHT) and the extracts showed an increase in the reduction potential which is enhanced with increasing concentrations (Figure 2). The aqueous: methanol $(20: 80, \mathrm{v} / \mathrm{v})$ extract in this assay, also showed the highest activity. At a concentration of 1 $\mathrm{mg} / \mathrm{ml}$, the reducing power of aqueous: methanol $(20: 80, \mathrm{v} / \mathrm{v})$ extract was very close to the reducing power of BHT and higher than the activity of the other four extracts. Such great activity is in accordance with its high total phenolic content. At $1 \mathrm{mg} / \mathrm{ml}$ maximum absorbance was found to be $0.27 \pm 0.03,0.42 \pm 0.04,0.97 \pm 0.08$, $1.78 \pm 0.15,1.98 \pm 0.16$, and $2.02 \pm 0.11$ for petroleum ether, water, acetone, methanol, aqueous: methanol $(20: 80, \mathrm{v} / \mathrm{v})$ and BHT, respectively.

The $\mathrm{IC}_{50}$ values (Table 2$)$ showed a significant $(\mathrm{p}<0.05)$ difference when BHT was compared with all the extracts. The $\mathrm{IC}_{50}$ values of methanol and acetone were not found to be significantly different $(\mathrm{p}>0.05)$ but these values were significantly different from the rest extracts. Petroleum ether and water extracts exhibited weaker ferric reducing power $\left(\mathrm{IC}_{50}>1000 \mu \mathrm{g} / \mathrm{ml}\right)$. 


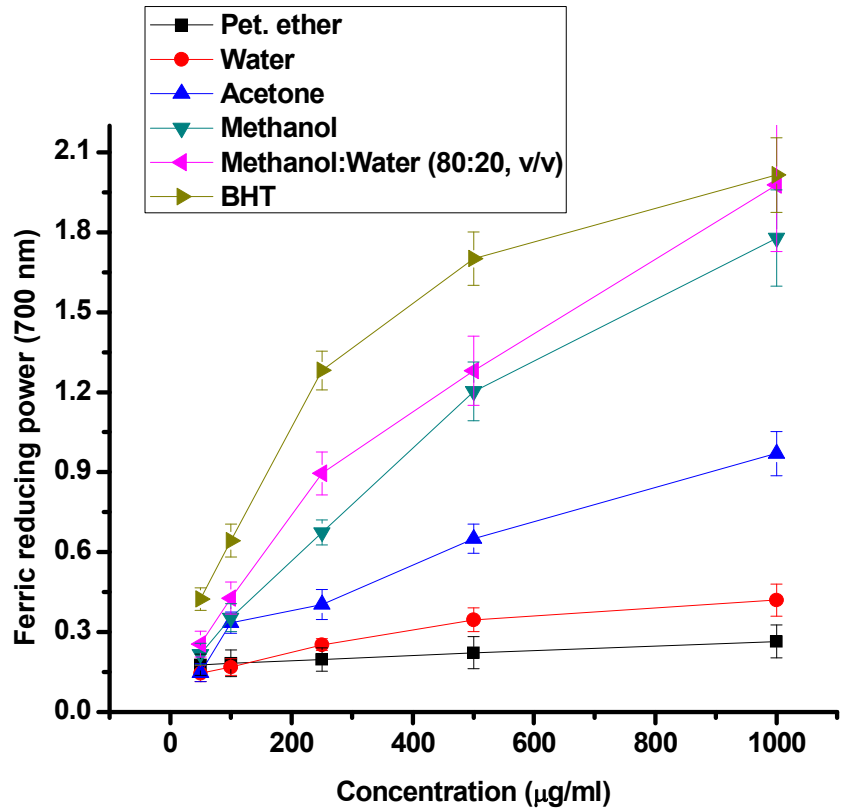

Figure 2 Ferric ion reducing power of petroleum ether, water, acetone, methanol, and aqueous: methanol (20:80, $\mathrm{v} / \mathrm{v})$ extracts from dried leaf of $L$. adoensis var. koseret at different concentrations $(\mu \mathrm{g} / \mathrm{ml})$. Values are average of triplicate measurements (mean \pm SEM).

\section{Antioxidant activity using phosphomolybdenum assay}

The results (Figure 3) indicated that aqueous: methanol (20:80, v/v) extract of $L$. adoensis var. koseret leaf had the highest total antioxidant activity $(105.32 \pm 10.67 \mathrm{mgAAE} / \mathrm{g})$ and the lowest total antioxidant activity $(4.86 \pm 1.68$ $\operatorname{mgAAE} / \mathrm{g})$ was found in the water extract. No significant difference $(\mathrm{p}>0.05)$ was found between the total antioxidant activity of petroleum ether and water extracts $(\mathrm{p}>0.05)$ and also between acetone, methanol, and aqueous: methanol (methanol: water, 80:20, v/v) extracts $(\mathrm{p}>0.05)$. Similar to the ferric reducing power the petroleum ether and water extracts showed the weakest total antioxidant activity.

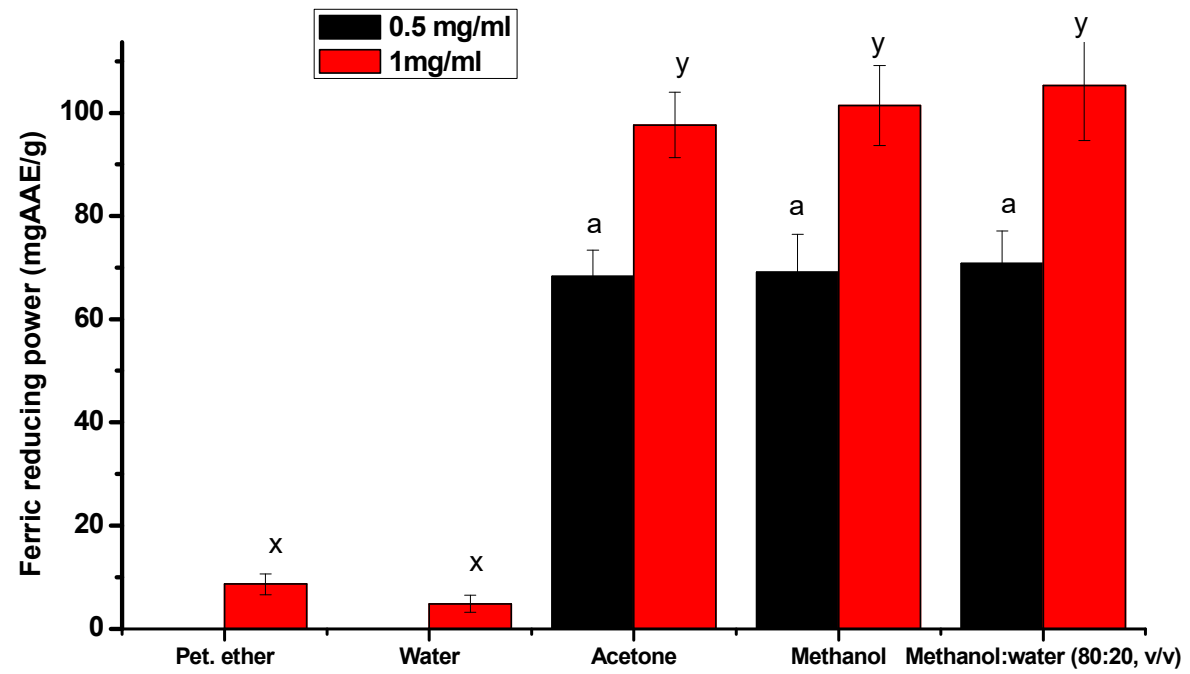

Figure 3 Total antioxidant capacity $(\mathrm{mgAAE} / \mathrm{g}$ ) of petroleum ether, water, acetone, methanol, and aqueous: methanol $(20: 80, \mathrm{v} / \mathrm{v})$ extracts from dried leaf of $L$. adoensis var. koseret. Values are average of triplicate measurements (mean $\pm \mathrm{SD}$ ). Values within the same concentration with different letters in the histogram bar are significantly different at $\mathrm{p}<0.05$.

\section{Ferrous chelating activity}

Metal chelating agents may have a dramatic effect on increasing the oxidation stability through blocking the pro- 
oxidant metal ions, and thus limiting the formation of chain initiators by preventing metal-assisted homolysis of hydroperoxides in lipid peroxidation (Praveen et al., 2012). Ferrozine can quantitatively form complexes with $\mathrm{Fe}^{2+}$. In the presence of chelating agents, the complex formation is disrupted resulting in a decrease in the red color of the complex. Measurement of the color intensity reduction at $562 \mathrm{~nm}$ wavelength allows estimation of the metal chelating activity of the chelators (Yamaguchi et al., 2000). In this assay, both the extracts and standard compounds were assessed for their ability to compete with ferrozine for $\mathrm{Fe}^{2+}$ in the solution. The percentage of iron chelating activities of all extracts and references were concentration-dependent (from 100 to $1000 \mu \mathrm{g} / \mathrm{ml}$ ) (Figure 4). At $1000 \mu \mathrm{g} / \mathrm{ml}$ the percentages of iron chelating capacity of the extracts and references decreased in the order of: EDTA $(99.67 \pm 0.1 .66 \%)>$ aqueous: methanol $(80: 20, v / v)(86.68 \pm 2.46 \%)>$ water $(82.42 \pm$ $1.76 \%)>$ methanol $(71.38 \pm 1.32 \%)>$ acetone $(71.04 \pm 1.58 \%)>$ BHT $(49.51 \pm 1.99 \%)>$ ascorbic acid $(41.46$ $\pm 0.66 \%)>$ petroleum ether $(35.57 \pm 3.84 \%)>$ quercetin $(24.46 \pm 1.24 \%)$. Aqueous: methanol $(20: 80, v / v)$ extract was better chelator than the other tested extracts.

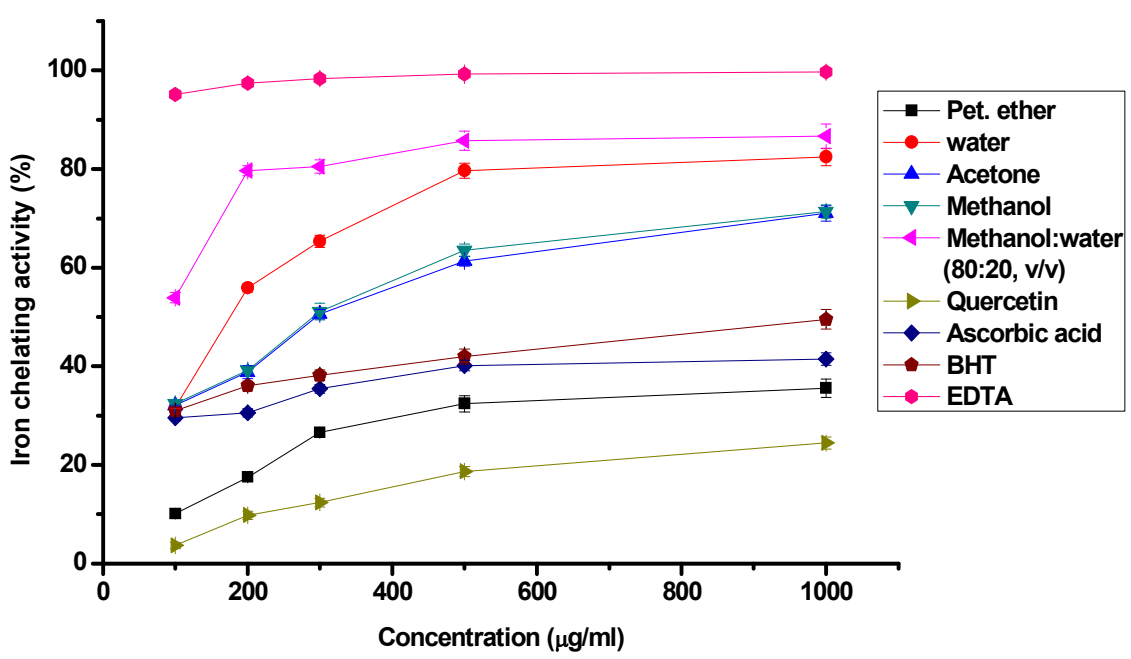

Figure 4 Ferrous ion chelating activity (\%) of petroleum ether, water, acetone, methanol, and aqueous: methanol $(20: 80, \mathrm{v} / \mathrm{v})$ extracts from dried leaf of $L$. adoensis var. koseret and controls (L-ascorbic acid, BHT, EDTA, and quercetin). Values are average of triplicate measurements (mean $\pm \mathrm{SD}$ ).

Table 2 shows no distinctive difference $(\mathrm{p}>0.05)$ between the $\mathrm{IC}_{50}$ values of methanol and acetone extracts, but these values were significantly higher $(\mathrm{p}<0.05)$ (weaker iron chelation) than the $\mathrm{IC}_{50}$ values of water and aqueous: methanol $(80: 20, \mathrm{v} / \mathrm{v})$ extracts. However, the $\mathrm{IC}_{50}$ value of aqueous: methanol $(80: 20, \mathrm{v} / \mathrm{v})$ extract and EDTA (one of the most powerful metal chelator ever known) were not significantly different $(p>0.05)$. Nevertheless, in this assay ascorbic acid and BHT showed weaker chelating activity $\left(\mathrm{IC}_{50}>1 \mathrm{x} 10^{2} \mu \mathrm{g} / \mathrm{ml}\right) \mathrm{of}$ iron (II) ions than acetone, water, methanol, and aqueous: methanol $(80: 20, \mathrm{v} / \mathrm{v})$ extracts, which is consistent with the findings of Yen et al. (2002) but greater than that of petroleum ether extract and quercetin.

\section{Correlation Analyses}

A relationship between phenolic content and antioxidant activity was extensively investigated (Bakchiche et al., 2013; Engeda, 2015). According to Paixao et al (2007), strong correlation between TPC and DPPH scavenging activity, and ferric reducing power was observed. A similar study by Mahmood et al. (2011) reported that selected Malaysian plant extracts displayed strong correlations between antioxidant ability and TPC. In this study, the dependence of antioxidant activity, obtained by different assays, in relation to the total phenolic and flavonoid contents, was also evaluated. The total phenolic content correlated well (Table 3$)$ with ferric reducing power $\left(\mathrm{R}^{2}\right.$ $=0.77, \mathrm{p}<0.05)$ and DPPH scavenging $\left(\mathrm{R}^{2}=0.88, \mathrm{p}<0.05\right)$, but weakly correlated with ferrous chelating activity $\left(\mathrm{R}^{2}=0.50, \mathrm{p}>0.05\right)$ and total antioxidant activity $\left(\mathrm{R}^{2}=0.32, \mathrm{p}>0.05\right)$. DPPH radical scavenging $\left(\mathrm{R}^{2}=0.07, \mathrm{p}>\right.$ $0.1)$, ferrous chelating activity $\left(R^{2}=0.14, p>0.1\right)$ and ferric reducing power $(0.35, p>0.1)$ weakly correlated but total antioxidant $\left(\mathrm{R}^{2}=0.73, \mathrm{p}<0.05\right)$ strongly correlated with the flavonoid contents in various solvent extracts of the herb. These results suggested that antioxidant activities of the extracts are not limited to phenolics and flavonoid compounds. The activity may also come from the presence of other antioxidant secondary metabolites in the extracts such as volatile essential oils, carotenoids, and vitamins (Javanmardi et al., 2003). 
Table 3: Correlations between antioxidant activities of the various solvent extracts of Datta and total phenolic and flavonoid contents $(p<0.05)$.

\begin{tabular}{lll}
\hline Antioxidant activities & Total phenolic $(\mathrm{mgGAE} / \mathrm{g})$ & Total flavonoid $(\mathrm{mgCAE} / \mathrm{g})$ \\
\hline DPPH scavenging $(\%)$ & $0.88^{*}$ & 0.07 \\
Ferric reducing power & $0.77^{*}$ & 0.35 \\
Total antioxidant activity & 0.32 & $0.73^{*}$ \\
Iron chelating activity & 0.50 & 0.14 \\
\hline
\end{tabular}

* indicates significance at $\mathrm{p}<0.05$

\section{Conclusion and Recommendation}

The study showed that total phenolic and flavonoid contents of $L$. adoensis var. koseret were highest in the aqueous: methanol $(20: 80, \mathrm{v} / \mathrm{v})$ and acetone extracts, respectively. Aqueous: methanol (80:20, v/v) extract showed strongest DPPH radical scavenging, total antioxidant, iron reducing power, and ferrous chelating activity. This suggests that the antioxidant activities of the tested extracts were closely associated with their total phenolic constituents. The study revealed that leaf extracts of $L$. adoensis var. koseret contain a considerable amount of phenolic compounds, and has significant antioxidant activity, which can be used as easily accessible source of natural antioxidants and as a possible food supplement or in pharmaceutical applications. However, the specific phenolic compounds or other components responsible for the antioxidant activity in various solvent extracts of $L$. adoensis var. koseret leaves are unknown. Therefore, further studies are needed to evaluate the in-vivo antioxidant potential of various solvent extracts and individual compounds in various animal models. Furthermore, research revealed the bioactive compounds present in the leaves of L. adoensis var. koseret have the potential to be used as possible natural substitutes for controversial synthetic antioxidants currently used in food preservation.

Acknowledgements: The authors would like to acknowledge the financial assistance provided by the Addis Ababa University and also extend thanks to Hawassa College of Education for the use of laboratory facilities. Professor Sebsebe Demisew of Biology Department, Addis Ababa University is acknowledged for identifying the plant material.

\section{References}

Abiola M., Asowata A., Gloria AO. and Anthony J. (2016). Assessment of the Polyphenolic Content, Free Radical Scavenging, Anti-inflammatory, and Antimicrobial Activities of Acetone and Aqueous Extracts of Lippia javanica (Burm.F.) Spreng. Pharmacognosy Magazine. 12(3): 353-362.

Alba NA. and Hasan N. (2009). In Vitro Antioxidant Activity of Methanolic Leaves and Flowers Extracts of Lippia Alba. Research Journal of Medicine and Medical Sciences. 4(1): 107-110.

Amarowicza R., Pegg R., Rahimi-Moghaddame P., Barld B. and Weilc J. (2004). Free-radical scavenging capacity and antioxidant activity of selected plant species from Canadian prairies. Food Chemistry. 84:551-562.

Bakchiche B., Gherib A., Smail A., Custodia G. and Grac, M. (2013). Antioxidant activities of eight Algerian plant extracts and two essential oils, Industrial Crops and Products. 46: 85-96.

Berhanu, A., Nigist, A. Wilber, L. (2001). Constituents of the Essential Oils from Wild and Cultivated Lippia adoensis Hochst. ex Walp. Journal of Essential Oil Research. 5:487-491.

Danielo R., Gilda GL., Stela SS., Humberto RB., Datse L., Celuta SA., Daniela SA. and Suzana GL. (2006). Ethnopharmacological study of two Lippia species from Oriximin'a, Brazil. Journal of Ethnopharmacology. 108:103-108.

Danielo RO., Gilda GL., Hnberto RB., Dai 'se L., Daniela SA., Celuta SA. and Suzana GL. (2007). Chemical and antimicrobial analyses of essential oil of Lippia origanoides H.B.K. Food Chemistry. 101:236-240.

Durairaj A., Vaiyapuri T., senthilkumar GP. and Mazumder UJ. (2008). Antioxidant and Free Radical Scavenging Effects of Lippia nodiflora. Pharmaceutical biology. 46 (11):762-777.

Engeda D. (2015). In Vitro Antioxidant and $\alpha$-Amylase Inhibition Activities of Spiced Red Chili Paste (Datta) from South Ethiopia. Ethiopian Pharmaceutical Journal. 31:93-106.

Engeda D. Geremew B. Gulelat DH. and H. P. Vasantha Rupasinghe (2015). Antioxidant and $\alpha$-amylase inhibition activities in vitro of various solvent extracts of Thymus schimperi Ronniger. Journal of Medicinal Plants Research. 9(15): 515-524.

Gemechu AB, Abdella G D, Engda D (2015). Antimicrobial Activity of Lippia adoensis var. koseret Against Human Pathogenic Bacteria and Fungi. American Journal of Clinical and Experimental Medicine. 3(3): 118123.

Hailu T., Endris M., Kaleab A. and Tsige G. (2005). Antimicrobial activities of some selected traditional Ethiopian medicinal plants used in the treatment of skin disorders. Journal of Ethnopharmacology. 100:168-175.

Hedberg I., Kelbesa E., Edwards S., Demssew S. and Persson E. (2006). Flora of Ethiopia and Eritrea. Vol. 5, Addis Ababa University, Addis Ababa, pp, 516-517. 
Hemlata P. and Pratima A. (2013). Effect of processing techniques on nutritional composition and antioxidant activity of fenugreek (Trigonella foenum-graecum) seed flour. Journal of Food Science and Technology.52(2):1054-60.

Junya de LS., Pâmela SS., Nádia RBR., Ezequias PS., Carlos LZ., Tânia MAA. and Lyderson F V. (2012). Chemical composition and antioxidant activity of Lippia species. Journal of Medicinal Plants Research. 6(27): 4416-4422.

Mahmood AA., Lee SC., Nigar N., Mazatulikhma MZ., Salehhuddin H. and Suhailah WQ. (2011). Antioxidant, Total Phenolic Content and Cytotoxicity Evaluation of Selected Malaysian Plants. Molecules.16: 3433-3443.

Mamun-Or-Rashid A., Sen M., Jamal M. and Nasrin S. (2013). A comprehensive ethno-pharmacological review on Lippia alba M. International Journal of Biomedical Materials Research. 1(1): 14-20.

Megersa M., Zemede A., Ensermu K., Abebe B. and Bizuneh W. (2013). An ethnobotanical study of medicinal plants in Wayu Tuka District, East Welega Zone of Oromia Regional State, West Ethiopia. Journal of Ethnobiology and Ethnomedicine. 9(68): 184-192.

Mohammad AE., Fereshteh P. and Ahmad RB. (2008). Iron chelating activity, phenol and flavonoid content of some medicinal plants from Iran. African Journal of Biotechnology. 7 (18): 3188-3192.

Naznin A. and Hasan N. (2009). In Vitro Antioxidant Activity of Methanolic Leaves and Flowers Extracts of Lippia Alba. Research Journal of Medicine and Medical Sciences. 4(1): 107-110.

Nigist, A., Sebsebe, D. (2009). Aromatic Plants of Ethiopia, Shama books, Addis ababa, Ethiopia, pp: 137-138.

Okonkwo C. and Ohaeri O. (2013). Insecticidal potentials of some selected plants. Journal of Chemical and Pharmaceutical Research. 5(4): 370-376.

Paixao M., Perestrelo R., Marques JC. and Camara JS. (2007). Relationship between antioxidant capacity and total phenolic content of red, rose' and white wines. Food Chemistry. 105:204-214.

Praveen N., Thiruvengadam M., Kim H., Praveen J. and Chung I. (2012). Antioxidant activity of Tinospora cordifolia leaf extracts through non-enzymatic method. Journal of Medicinal Plants Research. 6: 4790-4795.

Prieto P., Pineda M. and Aguilar M. 1999. Spectrophotometric quantitation of antioxidant capacity through the formation of a phosphomolybdenum complex: specific application to the determination of Vitamin E. Analytical Biochemistry. 269:337-341.

Rangachari B. and Savarimuthu I. (2011). Antidiabetic and Hypolipidemic effect of methanol extract of Lippia nodiflora L. in streptozotocin induced diabetic rats. Asian Pacific Journal of Tropical Biomedicine. 1:530 536.

Raul C., Valeria SC., Fbio C., Silva HT. and Ana MS. (2011). Chemical composition and therapeutic effects of Lippia alba (Mill.) N. E. Brown leaves hydro-alcoholic extract in patients with migraine. Phytomedicine. 18:1197-1201.

Riot S., Mariamawit Y., Ameha S. and Kaleab A. (2005). Radical scavenging activity of volatile oils of herbs traditionally used to spice cooking butter in Ethiopia. Ethiopian Pharmaceutical Journal. 23:7-14.

Rodrigo LF., Mauro SN., Jussara M., Maria MB. and Elita S. (2011). Identification of Antioxidant and Antimicrobial Compounds of Lippia Species by Bioautography. Journal of Medicinal Food. 14: 1-7.

Rohman A., Riyanto S., Yuniarti N., Saputra WR., Utami R. and Mulatsih W. (2010). Antioxidant activity, total phenolic, and total flavaonoid of extracts and fractions of red fruit (Pandanus conoideus Lam). International Food Research Journal. 17: 97-106.

Ruchi M. and Rekha V. (2017). Determination of total flavonoid and Phenol content in Mimusops elengi Linn. International Journal of pharmaceutical Sciences and Research. 8(12): 5282-5285.

Sandra LFS., Ricardo BO., Lauro ES. and Rosa HV. (2012). Chemical composition and antimicrobial activity of the essential oil of Lippia grandis Schauer (Verbenaceae) from the western Amazon. Food Chemistry. 134:1474-1478.

Suzana GJ., Paulo LD., Marcia GM., Simone NM. and Paulo M. (2011). Analysis of the Chemical Composition and Antimicrobial Activity of the Essential Oil from Lippia triplinervis Gardner (Verbenaceae). Journal of Essential. Oil Research. 23: 1-5.

Teblanche FC. and Kornelius G. (1996). Essential oil constituents of the genus Lippia (Verbenaceae) a literature review. Journal of Essential Oil Research. 8:471-485.

Velioglu YS., Mazza G.,Gao L., and Oomah BD. (1998).“Antioxidant activity and total phenolics in selected fruits, vegetables, and grain products." Journal of Agricultural and Food Chemistry. 46(10): 4113-4117.

Workalemahu M., Rohloff J. and Ariaya H. (2007). Volatile constituents and antioxidant activity of essential oils obtained from important aromatic plans of Ethiopia. Journal of Essential Oil Research. 10:465-474.

Yamaguchi F., Saito M., Ariga T., Yoshhiro Y. and Nakazawa H. (2000). Free radical scavenging activity and antiulcer activity of garcinol from Garcinia indica fruit. Journal of Agricultural and Food Chemistry. 48: 2320-2325.

Yen GC., Duh P. and Tsai H. (2002). Antioxidant and pro-oxidant properties of ascorbic acid and gallic acid. Food Chemistry. 79:307-313. 